\title{
RANCISCO SALZILLO, AUTOR DE LA VIRGEN DE LOS DOLORES DE LA VILLA REAL DE DOLORES (ALICANTE)
}

MARIANO CECILIA ESPINOSA

Departamento de Historia del Arte. Universidad de Murcia / Museo de Arte Sacro de Orihuela mariano.cecilia@um.es

GEMMA RUIZ ÁNGEL

Museo de Arte Sacro de Orihuela gemma@museodeartesacro.es

\begin{abstract}
Resumen: La Virgen de los Dolores de la villa alicantina de Dolores (Alicante), una de las fundaciones pías del Cardenal Belluga, ha sido tradicionalmente adscrita a la gubia del imaginero murciano Francisco Salzillo y Alcaraz. En este artículo documentamos la autoría de esta interesante pieza, enmarcándola en su contexto temporal y espacial, en relación a la construcción del templo donde se veneró hasta la actualidad, y a la propia obra del escultor, en concreto a su particular iconografía de la piedad o Virgen de las Angustias.
\end{abstract}

Palabras clave: Escultura / barroco / Salzillo / iconografía / piedad.

\section{FRANCISCO SALZILLO, AUTHOR OF VIRGIN OF DOLORES OF THE ALICANTE TOWN OF DOLORES}

Abstract: The Virgin of the Dolores of the Alicante town of Dolores, one of the foundations of Cardenal Belluga, has been traditionally attached to the gouge of the imaginary Murcia Francisco Salzillo and Alcaraz. In this article we document the authorship of this interesting piece, framing it in its temporal and spatial context, in relation to the construction of the temple where it was venerated until now, and to the sculptor's own work, in particular to his particular iconography of piety or Virgin of the Angustias.

Key words: Sculpture / Baroque / Salzillo / iconography / piety.

Las fuentes documentales son fundamentales para el conocimiento de la Historia del Arte, sí se pretende elaborar contenidos científicos de rigor y calidad, lejos del componente subjetivo que en muchas ocasiones rodean a esta disciplina con atribuciones sin fundamentación clara ni documentada. El trabajo que a continuación presentamos pretende mostrar la utilidad de una serie documental muy concreta, las visitas pastorales de los obispos a sus parroquias, para el estudio de las obras de arte pertenecientes al patrimonio eclesiástico.
Durante la Edad Moderna la visita pastoral era un ceremonial que permitía al obispo o en su representación a los cabildos catedralicios -que las llevaban a cabo en sede vacante-, el control exhaustivo de las parroquias de la diócesis y evidentemente, la aseveración y el reforzamiento del poder episcopal. La visita se registraba pormenorizadamente en un documento, que desde el punto de vista archivístico ha conformado series documentales específicas tanto en archivos parroquiales como epsicopales.

\footnotetext{
* Fecha de recepción: 15 de octubre de 2017 / Fecha de aceptación: 12 de enero de 2018.
} 
En este sentido, las visitas pastorales como fuente documental para el estudio de la historia del arte ha sido analizada por distintos autores ${ }^{1}$ y resulta fundamental en cuanto permite conocer no solo los datos relativos a la economía y administración de las diferentes parroquias sino también la evolución arquitectónica de los edificios que se visitan, ya que posibilitan establecer cronologías relativas para sus fases constructivas, así como el conocimiento del patrimonio artístico que conservaban en cada momento de su historia: la evolución de los ajuares litúrgicos, significativamente aqueIlos objetos muebles que formaban parte de la liturgia y del patrimonio de la comunidad que se visitaba, principalmente piezas de plata, ornamentos textiles, y esculturas, siendo posible su estudio a través de los inventarios, relación de altares, capillas y descripción de los mismos. Por otra parte, permite vislumbrar la aplicación de los decretos del Concilio de Trento, su grado de cumplimiento, así como los mandatos y orientaciones de los propios obispos en aspectos formales, litúrgicos y pastorales. En sentido más amplio nos muestran el estado de la diócesis respectiva y el desarrollo de la función pastoral de sus prelados.

En este trabajo el análisis de estas series documentales nos ha permitido documentar una obra muy relevante de la escultura barroca del Sureste y del patrimonio cultural valenciano, la Virgen de los Dolores, conservada en la población homónima alicantina. Este grupo escultórico ha sido tradicionalmente atribuido al escultor murciano Francisco Salzillo Alcaraz, de acuerdo a sus rasgos estilísticos y formales, adscripción en este caso acertada en cuanto a su autoría y menos precisa en lo que refiere a su cronología. Este último aspecto nos permite establecer la evolución estilística e iconográfica en la obra de un escultor de la relevancia de Salzillo que talló diversos conjuntos escultóricos similares al que analizamos en estas líneas, dentro de un modelo iconográfico propio de piedad o Virgen de las Angustias.

\section{Las fundaciones pías del cardenal Belluga; la villa real de Dolores}

Luis Antonio de Belluga y Mocada, obispo de Cartagena, ${ }^{2}$ fue el principal valedor de los Borbones durante la Guerra de Sucesión ${ }^{3}$ en el sur valenciano, a cuya cabeza se hallaba la ciudad de Orihuela, antigua capital de gobernación y segunda ciudad en importancia del Reino de Valencia. El obispo de Cartagena apoyó al aspirante borbón en el enfrentamiento bélico, con el que mantenía una buena amistad, cuestión esta que, tras su victoria, le procuró enormes influencias y un especial protagonismo en la época.

En el ámbito oriolano, que coincide prácticamente en la actualidad con la comarca del Bajo Segura, el obispo de Cartagena Luis de Belluga, llevó a cabo una de las repoblaciones más importantes que se produjeron en el Sureste Español, concretamente en unos territorios cercanos a la desembocadura del río Segura. El proceso colonizador tiene su génesis en una serie de tierras que Belluga, gracias a su gran influencia, consigue a través de cesiones de la ciudad de Orihuela, la villa de Guardamar $^{4}$ y las incautaciones realizadas a la casa de Rafal, -fruto del apoyo directo del marqués a la causa austracista-, logrando concentrar más de 40.000 tahullas de humedales y terrenos pantanosos e insalubres.

En estos territorios se inició un importante proceso colonizador en donde se produjo la desecación, el desmonte y finalmente la repoblación de esta zona. En ellos se proyectaron tres nuevas poblaciones: San Felipe de Neri, fundado por el propio

\footnotetext{
1 Entre la amplia bibliografía específica sobre este tema destacamos los trabajos de SÁNCHEZ PORTAS, Javier, Archivos Parroquiales de Orihuela, Arxius Valencians, 1, Consellería de Cultura, Educación y Ciencia, Generalitat Valenciana. 1985. PUEYO COLOMINA, Pilar, Las Visitas Pastorales: metodologia para su explotacion cientifica en Metodologia de la investigacion cientifica sobre fuentes aragonesas, VIII. Zaragoza 1993, pp. 215-268; Las visitas pastorales como fuente para el estudio de la religiosidad popular: el nivel de instruccion en la diocesis de Zaragoza a mediados del s. XVIII, en V Jornadas so- bre el estado actual de los estudios sobre Aragon, Zaragoza 1984, pp. 621-623; ANDREU ANDREU, A., La Visita pastoral como instrumentum laboris en la cura animarum de la diocesis de Cartagena, Murcia 1998, p. 6. Son imprescindibles los trabajos recogidos en "Memoria ecclesiae», vols. XIV y XV, La visita pastoral en el ministerio del obispo y archivos de la Iglesia, Oviedo 1999. Más recientes, destaca el artículo de GARCÍA HOURCADE, José Jesús; IRIGOYEN LÓPEZ, Antonio, "Las visitas pastorales, una fuente fundamental para la historia de Iglesia en la Edad Moderna". Anuario de Historia de la Iglesia, 2006. Sin mes, pp. 293-301.

2 El primero de los obispos de Cartagena en el siglo XVIII, Luis Antonio de Belluga y Moncada, cuyo episcopado se desarrolló durante el período 1704-1724, es considerado como una de las personalidades más importantes y relevantes de la historia murciana.

${ }^{3}$ Belluga consideró el enfrentamiento entre el aspirante Borbón y el Austria como una guerra de religión, participando activamente, solo hay que recordar que el futuro Felipe V le nombró Capitán General de los Reinos de Valencia y Murcia.

${ }^{4}$ CANALES MARTíNEZ, Gregorio, "Colonización del cardenal Belluga en las tierras donadas por Guardamar del Segura creación de un paisaje agrario y situación actual", Investigaciones Geográficas, número 3, 1985, pp. 143-160.
} 
Belluga; San Fulgencio y Nuestra Señora de los Dolores, cuyas advocaciones eran de especial predilección y devoción para el prelado murciano. Las tres villas, Dolores, San Felipe de Neri y San Fulgencio, fueron erigidas bajo una administración especial ya que dependían de un patronato real establecido en Murcia, ${ }^{5}$ a cuya cabeza estaba el rey, el obispo de Cartagena y su cabildo catedralicio, con una intervención constante del cardenal. ${ }^{6}$

\section{Fundación de la parroquia de Dolores: la construcción del templo}

El origen granadino del Cardenal Luis Belluga será fundamental para la introducción en la diócesis de Cartagena de la devoción a la Virgen de los Dolores, representada con su hijo muerto en su regazo. Evidentemente, el patronazgo de la Virgen de los Dolores en Granada es la causa de la gran devoción del prelado murciano hacia esta advocación, cuya iconografía moldeará singularmente el propio Francisco Salzillo. Esta devotio personal de Belluga se trasladará a la hora de fundar nuevas poblaciones bajo la denominación de los dolores de la Virgen ${ }^{7}$, tal como ocurre en las Pías Fundaciones, y en el caso concreto que aquí estudiamos.

La villa Real de Dolores se erige en 1735, posteriormente a San Felipe de Neri y San Fulgencio, respectivamente. ${ }^{8}$ No obstante, esta población terminará siendo la cabeza de las tres fundaciones, alcanzará un mayor desarrollo económico y urbanístico merced a su mejor situación, proximidad al río para su autoabastecimiento, y por sus tierras de mejor calidad para los cultivos. En este sentido, la población de Dolores alcanzó en poco tiempo la cifra considerable de 1489 habitantes, mientras en 1787 su crecimiento se situaba en torno a los 2117 moradores. Según Juan Bautista Vilar, este incremento poblacional tanto en Dolores como en San
Fulgencio se halla en relación con la regresión demográfica de Benejuzar y Campo de Salinas. ${ }^{9}$

El 4 de abril de aquel año se funda la parroquia de Nuestra Señora de los Dolores con su primer párroco a la cabeza, el sacerdote Sebastián Viala y Soto, ${ }^{10}$ designado por el obispo de Cartagena, en aquel momento Joseph de Montes. Unos meses después, el 23 de agosto, se mandó que se llevara a efecto la erección de la nueva parroquia y se admitiera al nuevo párroco que se había presentado conforme a lo establecido en la escritura de 8 de diciembre de 1729. El nuevo sacerdote tomó posesión de su beneficio en octubre de 1735.

En origen, el templo parroquial tal solo disponía del altar mayor, presidido por un lienzo de la Virgen de los Dolores, que representaba la advocación principal de la nueva parroquia. La construcción de la iglesia se dilató a lo largo del siglo XVIII, en concreto en el período comprendido entre 1735-1774, donde se desarrollaron distintas fases constructivas, documentadas indirectamente a través de las visitas pastorales llevadas a cabo en la parroquia por parte de la autoridad episcopal y en las referencias documentales contenidas en los libros sacramentales del archivo parroquial.

La primera etapa constructiva la podemos situar entre 1735 y 1752 con la ejecución de la primera mitad de la iglesia desde la cabecera, comprendiendo el altar mayor. Unas obras que concluyeron el 16 de diciembre de 1752 con la bendición de la nueva iglesia, y con el traslado al día siguiente del Santísimo Sacramento con toda la solemnidad debida. ${ }^{11}$ La segunda fase constructiva finalizó el 7 de diciembre de 1774 cuando se bendijo el resto del templo y se llevó a cabo de nuevo la traslación del Santísimo Sacramento, al día siguiente de la bendición, y la colocación del nuevo sagrario en el altar mayor, con facultad del obispo de la diócesis, José Tormo Juliá. ${ }^{12}$

\footnotetext{
${ }^{5}$ VILAR, Juan Bautista. Vilar, Orihuela una Ciudad Valenciana en la España Moderna, tomo I, 1981, p. 731.

${ }^{6}$ GIL OLCINA, Antonio; CANALES MARTínEZ, Gregorio, "Consolidación de dominios en las Pías Fundaciones del Cardenal Belluga (Bajo Segura)". Investigaciones geográficas. 1987, n 5, pp. 7-26.

7 BELDA NAVARRO, Cristóbal. POZO MARTíNEZ, Indalecio. Francisco Salzillo y la escuela de escultura de Caravaca. Universidad de Murcia, Servicio de publicaciones, 2016, pp. 60-62.

8 SÁEZ CALVO, José. La obra escultórica de las Iglesias de Pías Fundaciones y otros pueblos de la Vega Baja, editor J. Sáez، 2002.

${ }_{9}$ VILAR, Juan Bautista. Orihuela una Ciudad Valenciana en la España Moderna, tomo I, 198. pp. 209-211.

10 Certificación de Joseph Reale Valiente, Notario Apostólico y Secretario contador de la Junta y Diputación de Fundaciones, nombrado por los Señores Dean y Cabildo de la Catedral de Cartagena. El 2 de octubre de 1735 se bautiza al primer niño de la villa: Juan Antonio López Vas. Archivo parroquial de Dolores (en adelante A. P. D). Libro I de Bautismos, folio II. Despacho de 9 de mayo de 1735.

11 A. P. D. Libro $2^{\circ}$ racional de Defunciones, $2^{\mathrm{a}}$ parte, f. 9 -v. Lo firma Don José Falcón, Párroco,

12 A. P. D. Libro 2 de Matrimonios, f. $42-v$, aunque consta también en el Libro de Defunciones, f. 4. Lo anota y firma el párroco Don José Falcón.
} 


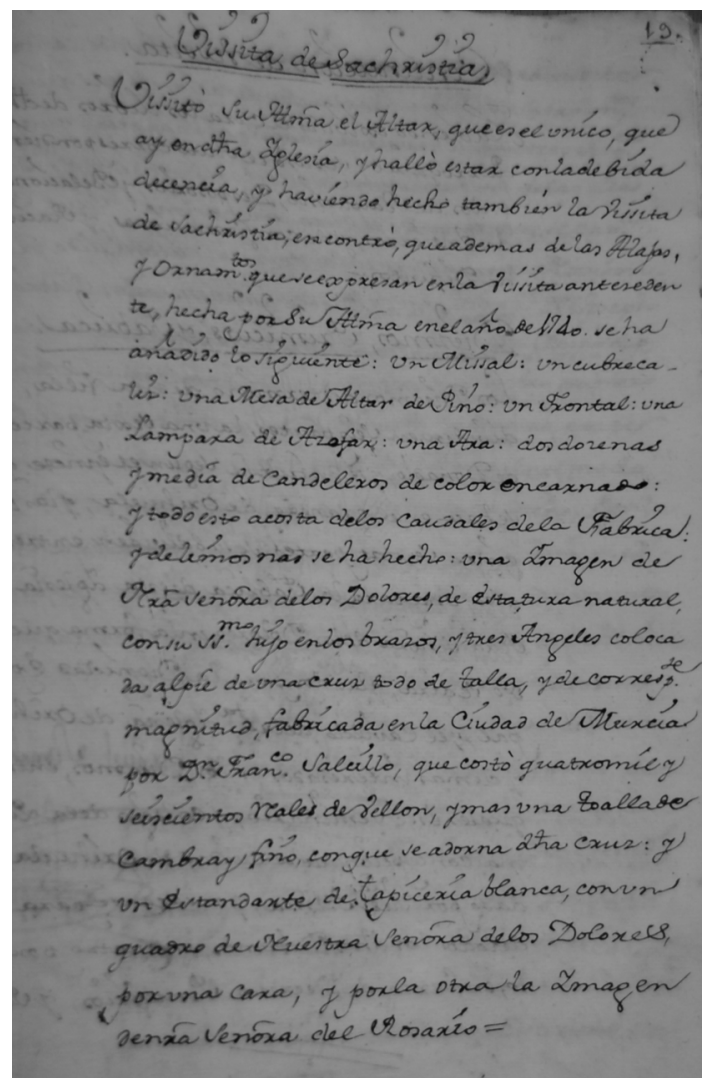

Fig. 1. Documento que acredita la autoría de Francisco Salzillo, el coste y el lugar de ejecución de la Virgen de los Dolores, venerada en Dolores (Alicante). Archivo Diocesano de Orihuela. Fondo Archivo Episcopal de Orihuela. Libro de Visitas Pastorales a la parroquial de la Villa Real de Dolores. Visita Pastoral de 1770. Sig.: 17.

En la tesis doctoral sobre el arquitecto oriolano Miguel Francia García, su autor Zamora Gómez ${ }^{13}$ señala la posibilidad de que inicialmente las obras fueran dirigidas por Miguel Francia Hernández, al igual que ocurrió en otro de los templos de las Pías Fundaciones, en la iglesia parroquial de San Felipe de Neri, de acuerdo a la estética constructiva presente en la fase inicial de la construcción. No obstante, la fábrica de este templo parroquial la concluirá Miguel Francia García, hijo del anterior, a quien correspondería la segunda fase constructiva de un edificio compuesto por una nave central con crucero no sobresaliente en planta, capillas laterales entre los contrafuertes, cabecera recta, -donde se sitúa el camarín cuadrangular de la Virgen de los Dolores-, flanqueado por la sacristía y la capilla de la Comunión. Mientras, a los pies del templo se localiza el coro alto y el campanario, situado sobre la primera capilla del lado Evangelio. El conjunto edilicio se cubre con bóveda de cañón con lunetos abiertos al exterior, cúpula de planta octogonal con tambor sobre el crucero y cupulines sobre las bóvedas vaídas de las capillas laterales.

\section{Francisco Salzillo. Aportación documental sobre la autoría de la imagen}

En la ciudad de Orihuela conocíamos la existencia de libros de visitas pastorales en las tres parroquias históricas de la ciudad; la iglesia de Santiago, la parroquial de las Santas Justa y Rufina y la parroquia del Salvador - S. I. Catedral de Orihuela-..$^{14}$ Por su parte, durante el proceso de catalogación de los fondos del Archivo Episcopal de Orihuela -que se conservaba por entonces en el Seminario Diocesano de esta ciudad-,$-^{15}$ constatamos la existencia de una amplia serie de visitas pastorales realizadas por los obispos de Orihuela a la mayoría de parroquias de la diócesis, en un amplio abanico temporal, desde prácticamente la creación del obispado en 1564 hasta bien entrado el siglo XX.

Entre ellas, localizamos un libro de visitas pastorales de la iglesia parroquial de la villa de Dolores correspondiente a los años de su fundación, que nos ha permitido documentar una gran obra de arte del patrimonio cultural valenciano, así como los orígenes constructivos del actual templo parroquial, tal como hemos expuesto en el apartado anterior. Como ejemplo de la importancia y de la utilidad de estas fuentes documentales publicamos aquí nuevos datos acerca de la imagen de la Virgen de los Dolores de la villa homónima que hemos localizado en un libro de visitas pastorales ${ }^{16}$ de la parroquia donde se venera el grupo escultórico atribuido hasta la fecha a Francisco Salzillo.

En los años inmediatos a la erección de la parroquial de los Dolores se veneró en la iglesia como

13 ZAMORA GÓMEZ, José Antonio, Miguel Francia: arquitecto del siglo XVIII en la antigua Gobernación de Orihuela, Universidad de Murcia, 2015, https://digitum.um.es/xmlui/handle/10201/47578 (consultado: 21-11-2018).

${ }^{14}$ SÁNCHEZ PORTAS, Javier, Archivos Parroquiales de Orihuela, Arxius Valencians, 1, Consellería de Cultura, Educación y Ciencia, Generalitat Valenciana. 1985.

${ }^{15}$ En la actualidad, este fondo documental está incorporado al Archivo Diocesano de Orihuela, situado en el Palacio Episcopal de Orihuela -sede del Archivo Histórico de la diócesis y del Museo de Arte Sacro-.

${ }^{16}$ Archivo Diocesano de Orihuela (En adelante A. D. O). Fondo Archivo Episcopal de Orihuela. Libro de Visitas Pastorales a la parroquial de la Villa Real de Dolores. Sig.: 17. 
titular del templo a Nuestra Señora de los Dolores representada mediante un lienzo ${ }^{17}$ que presidió el altar mayor hasta la ejecución de un grupo escultórico. En este sentido, en el inventario de alhajas y ornamentos que existían en la iglesia en el año 1740 se citan dos cuadros de la Virgen de los Dolores, uno de tamaño grande con marco negro, que sería la representación principal de la advocación principal en el templo, y otro más pequeño con marco dorado. ${ }^{18}$

Esta representación fue provisional, pues en poco tiempo se decidió recoger fondos para pagar la construcción de un grupo escultórico que despertara la devoción de los fieles a la iconografía del sexto dolor de María. El coste de la nueva imagen se satisfizo a través de limosnas y no a partir de los caudales de fábrica, sino mediante los fondos conseguidos mediante la denominada limosna de los Hornos. Esta limosna comenzó a recogerse en el año 1742 junto a otras que se habían ido adquiriendo del trigo, cebada y demás frutos con el fin de costear una imagen de Nuestra Señora de los Dolores y diferentes adornos y alhajas destinadas a honrar a la titular del templo. Este fondo de limosnas se destinaba para las festividades de la Virgen, adorno de su capilla, alhajas ${ }^{19}$ y todos los demás gastos necesarios para su culto, tal como se especifica en libro de visitas pastorales: "Esta limosna empezó en el año de 1742, con otras que se han ido recogiendo de trigo y cebada y demás frutos para la imagen que se ha hecho de talla de Nuestra Señora de los Dolores y otros adornos y alajas de ntra señora: $y . . .20 "$.

Los especialistas y conocedores de la obra de Francisco Salzillo no han dudado de su autoría en el caso de la Virgen de los Dolores de la villa alicantina, aunque documentalmente han sido pocos los datos conocidos sobre esta cuestión. En este sentido, en la misma visita localizamos una referencia directa a la imagen de la Virgen de los Dolores, en referencia a su descripción, autoría y coste de ejecución.
La descripción coincide perfectamente con la actual imagen que se conserva de clara adscripción salzillesca, se especifica las dimensiones del grupo escultórico y su composición, de tamaño natural, en donde aparece la Virgen María con su hijo muerto en los brazos, con tres ángeles al pie de la Cruz, adornada con una toalla de cambray fino: "...una imagen de Ntra. Señora de los Dolores, de estatura natural con su SSmo. Hijo en los brazos, y tres Ángeles colocada al pie de una cruz todo de talla y de correspondiente magnitud...21".

En cuanto a la autoría se especifica claramente que fue realizada en la ciudad de Murcia por el maestro escultor Francisco Salzillo, donde tenía establecido su taller. La obra costó 4600 reales de vellón y fue sufragada gracias a las limosnas aportadas por los fieles y devotos de la villa fundada por Belluga: "..., fabricada en la Ciudad de Murcia por $\mathrm{D}^{\mathrm{n}}$. Fran ${ }^{\circ}$. Salcillo, que costó quatromilseiscientos reales de vellon....22".

Con esta documentación queda patente la autoría de Salzillo y todo lo referente a su adquisición: obtención de fondos, lugar de los trabajos y pagos. Mientras, en lo que refiere a la cronología de la imagen podemos precisar una datación relativa que tendría como fecha límite ante quem el año 1742, tiempo en el que se comenzó a obtener limosnas para este fin, y post quem en 1748 , cuando ya sabemos que está construida según la descripción citada más arriba, que aparece reflejada en la visita pastoral de aquel año protagonizada por el obispo de Orihuela Juan Elías Gómez de Terán.

En las visitas pastorales estudiadas se recoge otra modalidad de limosna que de forma indirecta nos ayuda a especificar con mayor precisión la cronología de la imagen. Nos referimos a "la limosna de la Virgen para la misa de sábados", un donativo que comenzó a ser recaudado cuando la imagen debía estar ya ejecutada y expuesta en el templo para la veneración pública. En este senti-

\footnotetext{
17 A. D. O. Fondo Archivo Episcopal de Orihuela. Libro de Visitas Pastorales a la parroquial de la Villa Real de Dolores.Visita Pastoral de 1738. Sig.: 17. f. 3v.

${ }_{18}$ A. D. O. Fondo Archivo Episcopal de Orihuela. Libro de Visitas Pastorales a la parroquial de la Villa Real de Dolores. Visita Pastoral de 1740. Sig.: 17. f. 9v.

${ }_{19}$ Como ejemplo citaremos que en 1758 se realizó un frontal de tela de oro a expensas de la limosna de los Hornos que se recogía para la Virgen de los Dolores. Fondo Archivo Episcopal de Orihuela. Libro de Visitas Pastorales a la parroquial de la Villa Real de Dolores. Visita Pastoral de 1770. Sig.: 17.f. 46r.

20 A. D. O. Fondo Archivo Episcopal de Orihuela. Libro de Visitas Pastorales a la parroquial de la Villa Real de Dolores. Visita Pastoral de 1770. Sig.: 17. s.f.

21 Ibidem

22 Ibidem.
} 


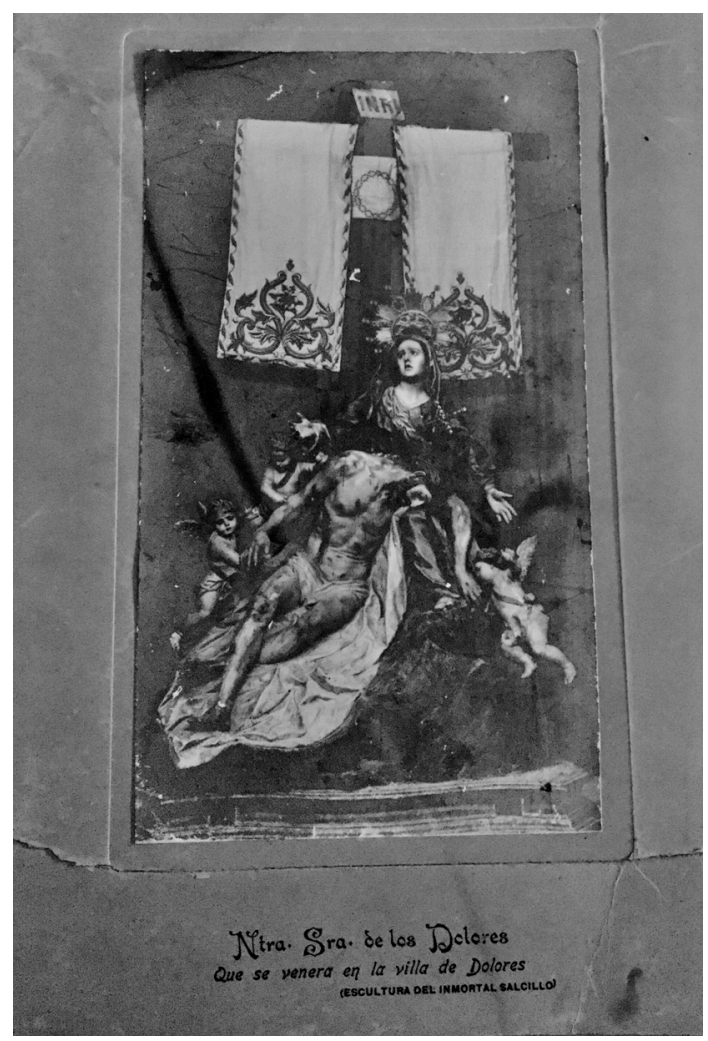

Fig. 2. Fotografía de la imagen de Nuestra Señora de los Dolores venerada en el templo parroquial de Dolores (Alicante). Anterior a 1936. Colección privada de María Dolores Botella Guillén.

do, las fuentes documentales nos indican que esta práctica comenzó en 1744: "Esta limosna se empezó a introducir en el año 1744 para Missa Cantada de Ntra. Señora en los sábados en la que se hace renovación del SSmo. Sacramento...23". Por tanto, podríamos establecer como cronología de la imagen el año 1743, una cronología más temprana a su homóloga de Lorca, y que como analizaremos a continuación, nos permite conocer mejor la evolución de este tipo iconográfico en la obra de Francisco Salzillo.

\section{Francisco Salzillo y el modelo iconográfico de la Virgen de las Angustias}

El escultor murciano Francisco Salzillo Alcaraz (1707-1783), considerado por sus contemporáneos ${ }^{24}$ como "celebrado escultor de España" y el "escultor del mayor crédito de estos reinos", se encuentra entre los grandes escultores del Barroco español. Su obra recuperó el esplendor de la escultura que desde el Renacimiento había decaído en el Levante, como digno continuador de los artistas renacentistas que trabajaron en el Sureste durante el quinientos: Jerónimo Quijano, Juan Inglés, los hermanos Ayala, o Jacopo Florentino, por citar algunos ejemplos destacados.

Es importante señalar la movilidad de Salzillo entre los reinos de Murcia y Valencia, tal como atestiguan sus numerosas obras conservadas en el sur valenciano, y en documentos notariales donde se desplaza a Orihuela para firmar contratos: por ejemplo, el documento publicado por Sánchez Portas para la realización del grupo escultórico de "la Sagrada Familia" destinado a la iglesia parroquial de Santiago. ${ }^{25}$ Pero esta intensa relación con el antiguo reino de Valencia, y en especial con la ciudad episcopal de Orihuela, viene de muy lejos, desde su propia iniciación en las artes, tal como indica el conde de la Viñaza destacando las palabras de la madre de Salzillo en cuanto a una hipotética formación en Roma del joven e incipiente escultor: "¿Para qué ir tan lejos, cuando aquí cer$\mathrm{ca}$, en Orihuela y Alicante, está Juan Bautista Borja llenando de adornos y floripondios, al gusto del día, los retablos y sillerías corales?". ${ }^{26}$ Esta anecdótica afirmación coincide con un dato demostrable, la estancia en Orihuela de un artista de gran prestigio como Juan Bautista Borja para la realización junto a Tomás Llorens de la sillería del coro catedralicio finalizada en 1718, por tanto, es muy posible su estancia en la sede catedralicia oriolana como aprendiz de Borja, tal como sugieren algunos autores. ${ }^{27}$

Salzillo creó un modelo iconográfico propio para representar la "piedad" que marcó el desarrollo de la escultura procesional y devocional en el sureste español hasta bien entrado el siglo XX. Los

\footnotetext{
23 Ibidem.

${ }^{24}$ ELDA NAVARRO, C., Estudios sobre Francisco Salzillo, Universidad de Murcia, servicio de publicaciones, 2015.

${ }^{25}$ SÁNCHEZ PORTAS, Javier, "El retablo de la Sagrada Familia de la parroquia de Santiago de Orihuela y el escultor Francisco Salzillo (nuevos datos)", revista Oleza, Orihuela, 1984.

${ }^{26}$ VIÑNAZA, CONDE DE LA, Adiciones al Diccionario histórico de los más ilustres Profesores de las Bellas Artes en España de D. Juan Agustín Ceán Bermúdez, Madrid, 1884, tomo III, p. 339. Citado en BELDA NAVARRO, C., Estudios sobre Francisco SalziIlo, Universidad de Murcia, servicio de publicaciones, 2015.

27 BELDA NAVARRO, C., Estudios sobre Francisco Salzillo, Universidad de Murcia, servicio de publicaciones, 2015, p. 77.
} 
cinco ejemplos de esta iconografía que salieron de la gubia de Salzillo fueron obras de las más relevantes de su producción, y en el contexto de la escultura barroca española. Los antecedentes iconográficos ${ }^{28}$ de los que posiblemente Salzillo pudo conocer esta iconografía fueron los grabados y estampas de las pinturas de la piedad de Annibale Carracci, las obras realizadas por otros escultores españoles en torno a este mismo tema -como Luisa Roldán o Juan de Adán-, y significativamente las referencias napolitanas próximas, como es el caso de la Virgen de la Caridad $^{29}$ (Cartagena), una pietá a la manera italiana, tipología consagrada por Miguel Ángel en la piedad del Vaticano, que se encargó en Nápoles desde Cartagena en 1723, y que ha sido atribuida al prestigioso escultor napolitano Giacomo Colombo, conocido por el padre de Francisco, el capuano Nicolás Salzillo.

El primer grupo escultórico de la obra de Francisco Salzillo que sigue esta iconografía es "la Virgen de las Angustias" encargada en 1738 por la cofradía de servitas establecida en la iglesia de San Bartolomé de Murcia. ${ }^{30}$ Esta magistral obra realizada para los servitas murcianos, es una de las grandes creaciones de Francisco Salzillo, y la primera donde sentó las bases de un modelo iconográfico con características propias que mantendrá y modificará paulatinamente en las décadas posteriores como resultado de su propia evolución como escultor, tal como podemos apreciar en los ejemplos de Dolores (Alicante), San Mateo de Lorca (desaparecido), Yecla, y el Convento de Capuchinas de Alicante. En cada una de estas obras quedará manifiesta la genialidad de Salzillo tanto en la composición, la talla, la policromía, la expresividad y las emociones que transmitirán unas imágenes cargadas de un hondo sentido teológico y devocional.

Esta obra, realizada en madera policromada y estofada, se compone de las imágenes de la Virgen María que sostiene en su regazo el cuerpo de su hijo muerto, sobre el monte Calvario en el momento en el que acaba de ser desenclavado de la cruz, presente en la escena, de la que cuelgan los lienzos empleados en el descendimiento de Cristo. El dramatismo de la escena se palia con las emociones que transmiten dos angelitos que en acti- tud doliente lloran el cuerpo muerto de Jesús. A nivel compositivo, la primera característica que encontramos es la estructura piramidal de la composición, -que evoca la piedad de Gregorio Fernández conservada en el Museo Nacional de Escultura en Valladolid. Una composición de marcado desequilibrio donde se contraponen la verticalidad que proporciona la imagen de María, cuyo vértice superior está marcado por la cabeza de la Virgen, -acentuada por la presencia de la Cruz vacía-, y la acusada horizontalidad que marca la disposición inerte del cuerpo de Cristo, dispuesta en paralelo de la roca del calvario.

El patetismo y el dolor del rostro de María, -lejos de toda idealización-, nos muestra el barroco en todo su esplendor. La imagen aparece sentada sobre la roca, dirige su mirada al cielo sobrecogida por un intenso dolor, sin comprender el significado del drama que está viviendo Compassio Mariae, mostrando el lado humano de la Virgen, al mostrar el sufrimiento del alma ante la perdida de un hijo. Con el antebrazo derecho sostiene el cuerpo de Jesús y extiende la izquierda en ademán declamatorio. El cuerpo de Cristo es de gran belleza, perfección anatómica y lograda policromía donde Salzillo conjuga la belleza formal y el ideal del cuerpo humano, con el drama del sufrimiento. Sin duda, la imagen desnuda de Cristo muerto, está dotada de unos valores anatómicos excepcionales, siendo apreciable, incluso, el peso del cuerpo inerte del Redentor, que descansa sobre el regazo de su madre. La presencia de angelitos que lloran el cuerpo de Cristo, besan sus manos y señalan sus heridas, además de aportar el sentimentalismo y la convulsión emocional a la escena, -al igual que ocurre en la Dolorosa (1754) de la Cofradía de Jesús (Murcia)-, serán el recurso para romper el equilibrio de la pirámide compositiva en las obras posteriores que realizó en esta iconografía, en concreto la "Virgen de los Dolores" (Dolores, 1744) y la "Virgen de las Angustias" (Lorca, 1746).

La calidad policromática de la obra de Salzillo se manifiesta claramente en esta pieza, con un excepcional cromatismo lleno de contrastes que oscilan desde la palidez de la Virgen angustiada, a los rosáceos en las encarnaciones de los angelitos y el

\footnotetext{
${ }^{28}$ Sobre la iconografía de la Virgen de las Angustias véanse principalmente: TRENS, Manuel. Iconografía de la Virgen en el Arte Español, "La Virgen de los Dolores", Editorial Plus Ultra, Madrid, 1946, pp. 223-232.

${ }^{29}$ PLAZA SANTIAGO. Francisco Javier. J., "La Virgen de la Caridad de Cartagena: Consideraciones sobre el origen de una iconografía" en Arte y Cultura en el primer centenario del templo de la Caridad de Cartagena. 1893-1993, Cartagena. 1993, pp. 165-187.

${ }^{30}$ Fue encargado a Francisco Salzillo el 27 de febrero de 1739, y estrenado con una solemne procesión celebrada el 1 de enero de 1741 , si bien la obra no estuvo definitivamente terminada hasta el 7 de febrero de ese año.
} 
matiz oliváceo del cadáver torturado de Jesús. Su sentido teológico se acrecienta con detalles como la sutil separación entre el cuerpo de Cristo y la roca mediante un sinuoso sudario para destacar que una vez consumada su pasión redentora, prevalece la naturaleza divina de Jesús. Un lienzo del que se sirve la misma Virgen para sujetarle, sin tocar el cadáver, todo para dejar patente la divinidad de Cristo, en un sentido eucarístico, donde el culto al Corpus Christi y la devoción a la Sangre de Cristo, en relación a su vez con el culto a la Vera Cruz como redentora, están presentes intrínsecamente en el sustrato teológico y cultual de la pieza.

\subsection{Los ejemplos de Dolores y Lorca}

La "Virgen de los Dolores" 31 de la villa alicantina de Dolores, objeto principal de este estudio, fue la segunda creación en esta iconografía de SalziIlo. Tanto en esta obra realizada en 1743, como en "la Virgen de las Angustias" tallada para la iglesia de San Mateo de Lorca en 1746, ${ }^{32}$ Salzillo introdujo notables variaciones, que modificarán sutilmente algunos de sus significados. ${ }^{33}$ En este sentido, la disposición de la Virgen con los brazos abiertos, que ya no sostiene el cuerpo de Cristo, nos muestra una madre oferente, que ofrece a su hijo, a la vez que se le puede añadir la cualidad de orante: ofrece a Dios y a los hombres, de ahí la perfecta exposición frontal y erguida del cuerpo del Hijo, e intercede en oración como mediadora. Esta es una idea más acorde con los nuevos tiempos de la Iglesia y también con la nueva filosofía cristiana de la Ilustración a la que Salzillo, sin duda, quería aproximarse, ${ }^{34}$ pues ya no es la madre quien sostiene el cuerpo de Cristo sino los angelitos, que en referencia a la talla de San Bartolomé han aumentado en número, -de dos a tres-, que además de aportar el toque sentimental al drama del Calvario, agudizan la separación entre lo divino y lo terrenal, excepcionalmente manifestada con el sutil empleo del lienzo del desenclavamiento que evita el contacto directo de Cristo con su Madre y la roca del Calvario, al igual que ocurre en todas las obras de esta iconografía

El rostro de la Virgen y su expresión se aproxima al modelo de Dolorosa de Salzillo, significativamente la idea de imagen abierta y declamatoria, tal como indica el profesor Belda en su análisis de la extraordinaria imagen de vestir de la cofradía de Jesús, que protagoniza la mañana del Viernes Santo murciano. ${ }^{35}$ Los paralelos están muy claros, Salzillo recurre tanto en los ejemplos de Dolores y Lorca, como en la propia Dolorosa, a acentuar el gesto y la expresividad de la imagen, aspecto que repetirá posteriormente en muchas de sus obras.

\subsection{La evolución del modelo iconográfico: los grupos escultóricos de las Capuchinas de Alicante y de Yecla}

El escultor Francisco Salzillo no volverá a tratar este modelo iconográfico hasta la década de 1760 con los encargos de Alicante y Yecla respectivamente. ${ }^{36}$ En 1762 realizará para el Convento de los Triunfos del Santísimo Sacramento de las Madres Capuchinas (Alicante), por encargo de Juan Bautista Caturla, vecino de Alicante, teniente de alguacil del Santo Tribunal de la inquisición de Murcia, un conjunto escultórico bajo la advoca-

\footnotetext{
${ }^{31}$ La Virgen de los Dolores fue intervenida en 1939, tras acabar la guerra civil por el escultor valenciano José Ballester Badía. Este artista había nacido en Valencia en 1902 y su vinculación artística con el Bajo Segura se debe a la realización de una imagen de San Fulgencio (1939) para la población homónima, la Virgen Dolorosa del municipio de Dolores (1940) y las restauraciones para esa misma población de la citada Virgen de los Dolores y San Pascual Bailón.

La presencia de escultores valencianos se debía a la demanda de escultores que existió en los primeros años de la posguerra para la creación de nuevas imágenes de trasunto religioso que habían sido destruidas en los primeros momentos de la guerra o para intervenciones de las imágenes que habían sufrido graves deterioros. En la zona se recurrió mayoritariamente a escultores valencianos: Enrique Galarza, Manuel Ponsoda, José Dies por citar algunos ejemplos destacados. No obstante las intervenciones realizadas tanto a nivel escultórico como con fines de restauración por José Sánchez Lozano relacionado con el ámbito murciano también fueron notables. En este sentido, destacaremos la realización para Orihuela de la imagen de Nuestro Padre Jesús Nazareno, una de sus obras maestras.

32 El grupo escultórico de Nuestra Señora de las Angustias de Lorca (Murcia) fue destruido durante la Guerra Civil, conocemos los detalles de su realización gracias a la conservación de fotografías antiguas, que nos muestran su cercanía con la Virgen de los Dolores de la localidad alicantina de Dolores (Alicante).

${ }^{33}$ La transición desde el modelo inicial de la "Virgen de las Angustias" de San Bartolomé (1741) hacia los ejemplos de Dolores y Lorca quedan evidenciados en el boceto de la "Virgen de las Angustias" conservado en la iglesia de las Mercedarias de Lorca, atribuido a Francisco Salzillo.

${ }^{34}$ RAMALLO ASENSIO, Germán, "Francisco Salzillo y la estética neoclásica", Imafronte, n 14, p. 240, 1999, Murcia.

35 BELDA NAVARRO, Cristóbal, Estudios sobre Francisco Salzillo, Universidad de Murcia, servicio de publicaciones, 2015, p. 125.

${ }^{36}$ Estos dos ejemplos están relacionados con el modellino de la "Virgen de las Angustias" del convento de Capuchinas de Murcia (atribuido a Francisco Salzillo), significativamete con el encargo realizado para Yecla.
} 
Tabla 1

RELACIÓN DE OBRAS DOCUMENTADAS DE FRANCISCO SALZILLO QUE REPRESENTAN SU MODELO DE "VIRGEN DE LAS ANGUSTIAS"

\begin{tabular}{|c|c|c|c|c|}
\hline Obra & Procedencia & Cronología & Ubicación & Comitente \\
\hline $\begin{array}{l}\text { Nuestra Señora } \\
\text { de las Angustias }\end{array}$ & $\begin{array}{l}\text { Iglesia de San } \\
\text { Bartolomé, } \\
\text { Murcia }\end{array}$ & 1741 & $\begin{array}{l}\text { Iglesia de San } \\
\text { Bartolomé, } \\
\text { Murcia }\end{array}$ & $\begin{array}{l}\text { Cofradía de } \\
\text { Servitas }\end{array}$ \\
\hline $\begin{array}{l}\text { Nuestra Señora } \\
\text { de los Dolores }\end{array}$ & $\begin{array}{l}\text { Iglesia de } \\
\text { Nuestra Señora } \\
\text { de los Dolores, } \\
\text { Dolores } \\
\text { (Alicante) }\end{array}$ & 1743 & $\begin{array}{l}\text { Iglesia } \\
\text { parroquial de } \\
\text { Nuestra Señora } \\
\text { de los Dolores }\end{array}$ & $\begin{array}{l}\text { Parroquia de } \\
\text { Dolores }\end{array}$ \\
\hline $\begin{array}{l}\text { Nuestra Señora } \\
\text { de las Angustias }\end{array}$ & $\begin{array}{l}\text { San Mateo, } \\
\text { Lorca }\end{array}$ & 1746 & $\begin{array}{l}\text { Desaparecida en } \\
1936\end{array}$ & $\begin{array}{l}\text { Costeada por el } \\
\text { párroco Juan } \\
\text { Ponce de León. }\end{array}$ \\
\hline $\begin{array}{l}\text { Nuestra Señora } \\
\text { de las Angustias }\end{array}$ & $\begin{array}{l}\text { Convento de los } \\
\text { Triunfos del } \\
\text { Santísimo } \\
\text { Sacramento de } \\
\text { las Madres } \\
\text { Capuchinas } \\
\text { (Alicante) }\end{array}$ & 1762 & $\begin{array}{l}\text { Convento de los } \\
\text { Triunfos del } \\
\text { Santísimo } \\
\text { Sacramento de } \\
\text { las Madres } \\
\text { Capuchinas } \\
\text { (Alicante) }\end{array}$ & $\begin{array}{l}\text { Juan Bautista } \\
\text { Caturla, vecino } \\
\text { de Alicante, } \\
\text { teniente de } \\
\text { alguacil del } \\
\text { Santo Tribunal } \\
\text { de la inquisición } \\
\text { de Murcia. }\end{array}$ \\
\hline $\begin{array}{l}\text { Nuestra Señora } \\
\text { de las Angustias }\end{array}$ & $\begin{array}{l}\text { Iglesia de San } \\
\text { Francisco, Yecla } \\
\text { (Murcia) }\end{array}$ & 1763 & $\begin{array}{l}\text { Iglesia de la } \\
\text { Purísima, Yecla, } \\
\text { (Murcia) }\end{array}$ & $\begin{array}{l}\text { Fray Miguel } \\
\text { Guardiola, } \\
\text { franciscano } \\
\text { terciario. }\end{array}$ \\
\hline
\end{tabular}

ción de "Nuestra Señora de las Angustias", que mantendrá en lineas generales el modelo establecido desde 1741 pero con sutiles, y a la vez notables variaciones.

En la materialización de este encargo se observan, a diferencia de los ejemplos realizados en décadas anteriores, una mayor contención expresiva en el rostro de la Virgen, donde el dolor se atenúa, a la vez que se escenifica un menor grado de patetismo, dentro de una estética más rococó con aires clasicistas en la que el tratamiento de las formas se caracterizan por la suavidad y la elegancia.

En el caso del último encargo realizado al escultor donde volvió a tallar este tipo iconográfico, el grupo escultórico de "Nuestra Señora de las Angustias", del convento de San Francisco de Yecla
(1763), por iniciativa del franciscano terciario Fray Miguel Guardiola, observamos de nuevo cambios al respecto de todas las obras anteriores, incluida la pieza que un año antes había ejecutado para Alicante. En este sentido, la obra en su conjunto pierde en expresividad, gana en riqueza y colorido, significativamente gracias al empleo de una riqueza policromática en la vestimenta de la Virgen, fundamentada en la utilización como recurso decorativo de ramos estofados y dorados.

Tal como señala el profesor Belda Navarro, se potencia el lenguaje expresivo de las miradas y esa tendencia que analizamos en la pieza de Alicante donde se tratan con suavidad las formas se agudizan en este ejemplo, tal como puede apreciarse en la cabeza de Cristo que descansa con mayor delicadeza, si cabe, en el regazo de su madre. 


\section{A modo de conclusión}

El análisis comparativo entre los grupos escultóricos que prepresentan el modelo iconográfico de piedad o Virgen de las Angustias en la extensa obra del escultor murciano Francisco Salzillo Alcaraz muestran el establecimiento de una tipología con características comunes que se mantienen en todos los ejemplos estudiados. Destacaremos en primera instancia el esquema compositivo que se establece desde el primer grupo escultórico de San Bartolomé y se mantiene en toda la serie con ligeras variaciones, cuyas características se podrian resumir en la estructura piramidal de la composición, el foco de atención centrado en la Virgen en su expresión de máximo dolor, el cuerpo inerte, mortal y a la vez divino, que yace levemente sobre el regazo protector de la Virgen, la presencia emotiva de los angelitos como recurso emocional para despertar la devoción y la compasión de los fieles ante la escena de dolor, y a su vez, de la soledad de una madre que ha perdido a su hijo.

La vestimenta de la Virgen varía en los distintos ejemplos estudiados, no así ocurre con la imagen de Cristo, prácticamente inalterable en todas las obras de esta temática en Salzillo. En este sentido, es interesante el estudio anatómico, así como la utilización de elementos comunes en todas las obras de la producción salzillesca, como es el caso del tratamiento del paño de pureza, -perizonium-, que siempre aparece introducido entre las piernas, de igual modo que en la amplia mayoría de sus crucificados, -crucificados de Jumilla (1750), San Eloy (1756), la Agonía de Orihuela (1774), o en obras de gran tamaño como son los casos del "Cristo del Perdón" (1775, Murcia) y del "Cristo de Zalamea" de Orihuela (circa 1775). Asimismo, también lo emplea en una iconografía

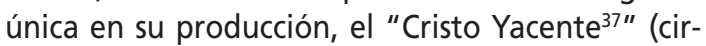
ca 1774), del convento de San Juan de la Penitencia en Orihuela.

El modelo de Virgen de las Angustias se perpetuó hasta el siglo XX y fue repetido por discípulos como José López con "la Virgen de las Angustias" de El Salvador en Caravaca (1769), escultores como Marcos Laborda con "la Virgen de laa Angustias" de la iglesia de la Magdalena en Cehegín (1785) hasta seguidores muy posteriores como José Sánchez Lozano con "la Virgen de las Angustias" de Redován (Alicante), por citar algunos ejemplos destacados.

El hallazgo de la documentación que presentamos en este artículo, ayuda a encajar la única obra de esta iconografía no documentada lo que pemite desarrollar y comprender el proceso creativo y evolutivo del propio Salzillo en una tipologia tan concreta, y de tanta relevancia devocional en Murcia y su entorno inmediato, en este caso el sur valenciano, después del fomento de su culto por el propio Cardenal Belluga, plasmado excepcionalmente por el mejor escultor del momento, Francisco Salzillo, "el escultor de mayor crédito de estos reinos".

\footnotetext{
${ }^{37}$ Esta interesante pieza fue incluida en 1973 por primera vez en los catálogos de Salzillo por Gómez Piñol y Belda Navarro. Se trata de una imagen que se relaciona formalmente con el Cristo de la Agonía de la V. O. T., por lo que se sitúa cronológicamente en el mismo momento. GÓMEZ PIÑOL, Emilio, y BELDA NAVARRO, Cristóbal, "Catálogo", en Salzillo (1707-1783). Exposición antológica. Iglesia de San Andrés - Museo Salzillo Madrid, 1973.
} 